\title{
Entre reescritura e expansão do texto: da gênese à criação pós- editorial de Proust e os signos, de Gilles Delenze
}

Thiago Leão Antunes

\section{O problema da reescrita e da ampliação: no caminho de Proust et les signes}

UMA OBRA, DOIS TÍTULOS, DUAS AMPLIAÇÕES, TRÊS ARTIGOS PRELIMINARES, TRÊS EDIÇÕES SIGNifiCATIVAMENTE MODIFICADAS. Proust e os signos (1964; 1970; 1976), em sua edição atual é aberto por um prefácio que, apesar de indicar ao leitor a presença de camadas de texto agregadas em momentos diferentes, tende a sugerir que essa configuração teria, em si mesma, pouca importância. De acordo com Gilles Deleuze (1925-1995), teríamos diante de nós um simples prolongamento da reflexão iniciada em 1964 e à qual se somariam novos enfoques, completamente independentes e separados pelas duas partes em que se divide o livro. Se houve intervenções no texto, elas se restringiriam à finalidade um tanto caridosa - facilitar nossa vida, ao torná-lo ainda mais claro:

A primeira parte deste livro concerne a emissão e a interpretação dos signos tal como são apresentados em Em busca do tempo perdido. A outra parte, que foi adicionada em bloco na segunda edição, trata de um problema diferente: a produção e a multiplicação dos signos em si, do ponto de vista da composição da Recherche. Essa segunda parte é atualmente dividida em capítulos, na esperança de torná-la ainda mais clara. Ela termina com um texto apresentado num obra coletiva na Itália (Saggi e ricerche di Letteratura Francese, XII, Bulzoni édit., 1973) e cuja versão foi modificada. ${ }^{2}$

No entanto, o percurso não é tão simples. Podemos encontrar sucessivas intervenções em diferentes âmbitos. Isso sem levar conta o fato de Deleuze, nessa abertura, omitir algumas das etapas interpostas às edições, com artigos preliminares, os quais são responsáveis por deslocamentos fundamentais à compreensão dos rumos que essa obra tomará ao longo dos treze anos que compreendem seu período de gênese pós-editorial. $\mathrm{O}$ autor enfatiza que o leitor deveria atentar-se às mudanças em relação às perspectivas através das quais ele aborda os escritos de Marcel Proust: na primeira parte, "Les signes", o enfoque dado adotaria como eixo único o nível narrativo, com suas dinâmicas, mas restringindo a análise àquilo que se desenrola entre as personagens; a

${ }^{1}$ O presente artigo foi desenvolvido a partir de uma comunicação apresentada no XIV Congresso Internacional da Associação de Pesquisadores em Crítica Genética, em outbro de 2019, na Universidade Federal do Paraná (UFP), com título "Proust e os signos de Gilles Deleuze: entre a reescritura e a expansão do texto".

${ }^{2}$ Deleuze, G. Proust et les signes. Paris: Presses Universitaire de France, 1976, p. 5, tradução nossa: "La première partie de ce livre concerne l'émission et l'interprétation des signes tels qu'ils se présentent dans $A$ la recherche du temps perdu. L'autre partie, qui fut ajoutée en bloc à la seconde édition, traite d'un problème différent : la production et la multiplication des signes eux-mêmes, du point de vue de la composition de la Recherche. Cette deuxième partie est maintenant divisée en chapitres, dans un vœu de plus grande clarté. Elle se termine sur un texte qui a paru dans un volume collectif en Italie (Saggi e ricerche di Letteratura Francese, XII, Bulzoni édit., 1973) et dont la version est remaniée". 
segunda, "La machine littéraire", por outro lado, seria caracterizada por um ponto de vista mais amplo, que se ocupa de fenômenos ligados ao processo de criação do romance e dos efeitos em potenciais da leitura. Operação essa que tende ao apagamento dos impasses e tensões próprios de um objeto que sofre modificações ao longo do tempo, forçando uma unidade que é problemática. Nesse comentário que serve de preâmbulo à última edição de Proust et les signes, Deleuze precipita o leitor a crer numa coesão pressuposta que é, se não enganosa, ao menos uma aparência fabricada na superfície e que se desmancha tão logo sejam comparadas as sucessivas versões desse texto. A atual edição de Proust et les signes é, ao contrário do que sugere o autor, resultado de uma relação de longa data com as obras de Proust e, de forma alguma, limitada à integralidade do livro em questão. O diálogo travado com Proust permeia de fragmentos difusos o conjunto de suas publicações até o último livro: um discurso que não se faz especializado, nem se quer esgota o tema que propõe estudar.

Como veremos, as primeiras alusões a Proust se fazem presentes desde os primeiros artigos de Deleuze, em meados dos anos 40. O que, de início, consistia em menções esparsas torna-se cada vez mais consistente e sistemático. Em outubro de 1963, ano de comemoração dos cinquenta anos de publicação de Du côté de chez Swann, aparece na Revue de Métaphysique et de Morale um texto de Deleuze intulado "L'unité de A la recherche du temps perdu" - um artigo preliminar, anunciando o livro a ser publicado dentro de alguns meses, Marcel Proust et les signes. Seis anos depois, em 1970, esse texto será acrescido de um capítulo inédito, além de modificações pontuais quanto a primeira versão. O título, porém, não será mais o mesmo: o livro será conhecido, a partir de então, como Proust et les signes, tal como fora referenciado por engano, em "Proust et les noms" de Roland Barthes. Trechos desta nova edição, posteriormente modificados, serão apresentados na Quinzaine Littéraire ${ }^{4}$, meses antes.

Em 1973, como indicado por Deleuze no prefácio do livro, um novo artigo sobre Proust: "Présence et

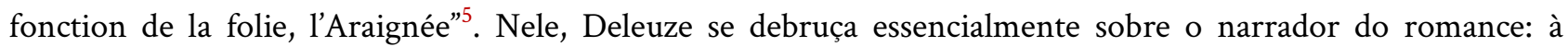
imagem da aranha, que só percebe do mundo aquilo que toca em algum ponto a extensão de sua teia, o narrador proustiano não vê o mundo, sendo capaz de notar apenas aos fenômenos que conseguem sensibilizar um campo de percepção singularmente limitado por sua loucura - elemento massivamente presente na Recherche e em seus personagens. Essa característica será referida, numa mesa redonda com Gérard Genette e Roland Barthes no evento "Proust et la nouvelle critique", como um "problema relativamente recente", nas palavras de Deleuze. O livro será novamente ampliado, tendo sua segunda parte reestruturada em 1976, a qual passa a incorporar esse artigo publicado na revista italiana de literatura francesa.

Em paralelo aos textos que estão vínculados a essa etapa de gênese pós-editorial, de 1963 a 1976, as alusões a Proust passam a se repetir entre escritos que não estão diretamente relacionados a esse processo: desde Nietzsche et la philosophie (1962), contaremos com sua presença em Le bergsonisme (1966), além de Différence et Répetition

${ }^{3}$ BARThes, R. "Proust et les noms" (1967), in: Le degré zéro de l'écriture, suivi des Nouveux Essais Critique. Paris: Éditions du Seuil, 1972, p. 315-371.

${ }^{4}$ Deleuze, G. "Proust et les signes", in: Quizaine Littéraire, no 103, 1970.

${ }^{5}$ DeleuZe, G. "Présence et fonction de la folie, l’Araignée”, in: Saggi e ricerche di Letteratura Francese, XII, 1973.

${ }^{6}$ Deleuze, G. "Table ronde sur Proust”, in: DELEUZE, G. Deux regimes de fous: textes et entretient 1975-1995. Paris: Éditions de Minuit, 2003, p. 30, tradução nossa: "problème rélativement récent pour moi”. 
(1968), Logique du sens (1969), L’Anti-EEdipe (1972), Mille Plateux (1980) e até em seus últimos livros Qu'est-ce que la philosophie?(1992) e Critique et Clinique (1993).

Essa longa trajetória está longe de poder ser reduzida à mera partição do livro em dois segmentos ou até a mesmo a um impulso de tornar mais clara a forma em que a reflexão é exposta ao leitor. Inclusive, vale destacar, tal divisão só configura na última edição da obra, em 1976. Se não contamos com manuscritos ou datiloscritos de tais versões, seria equivocado considerar de segunda ordem essa série de documentos publicados - muitos dos quais não chegaram a ser copilados nas coletâneas póstumas, refletindo em certos aspectos a pouca importância atribuída a eles por seus comentadores que organizaram tais volumes. A obra de Deleuze apresenta diversas resistências e obstáculos às abordagens genéticas ${ }^{7}$ : não há acervos dedicados ao autor a serem consultados, apenas documentos avulsos dos quais boa parte são cartas; uma prática recorrente de destruição dos manuscritos após a publicação. Todas circunstâncias desfavoráveis para as pesquisas que têm por objetivo recuperar em alguma instância rastros de um trabalho de escritura.

E, no entanto, documentos de processo como esses não foram conservados no caso de Proust et les signes. O que resta, então? Apenas documentos que, supostamente, seriam pouco produtivos no que diz respeito a dissemelhanças profundas e rasuras através das quais seria possível extrair os caminhos percorridos pela escritura. Não há esboços, nem manuscritos que dêem a ver um processo. Não haveria nesse caso qualquer elemento capaz de nos conduzira novas possibilidades interpretativas, ao menos teoricamente. Não haveria também o que recuperar do trabalho de criação apaneas por meio do acesso a versões impressas, tais quais chegaram às mãos do leitor. Porém, em se tratando de uma obra que se desenvolve aos olhos do público por mais de uma década, suas fases sucessivas constituem, em si, um dossiê do processo de criação. Se os documentos de caráter privado são, geralmente, caracterizados por intervenções mais numerosas e deslocamentos mais profundos, os indícios encontrados nas etapas pós-editoriais, iriam na direção oposta: ocorrem num âmbito público e não estão limitadas às pulsões e interferências de um scriptor. O processo de reescrita delineado nas próprias versões publicadas intervenções significativas, ao lado de incontáveis fatores não menos importantes: as condições de produção, recepção e circulação de cada nova publicação.

As mudanças observáveis no texto com relação à pontuação, substituições lexicais, operações de cesura na paragrafação, supressões, dentre as diversas possibilidades de mundanças encontradas no curso das versões. Dando a ver, de certo modo, rasuras que não são materialmente dadas, porém que se mostram quando tornadas vísiveis nos gestos particulares de tal processo de reescritura, que :

Assim como o grito gera o silêncio, a rasura, que equivale a uma emergência ou a um grito, gera um tempo de espera e um silêncio mais ou menos longo. A rasura poderá ser igual a um grito especial oriundo do mais profundo do ser, não somente de quem tem a pluma ou digita no teclado, mas da comunidade representada da qual é porta-voz. O silêncio gerido acentuará o laço desconhecido que virá e a rasura. Sem a rasura, não há silêncio nem enigma. A rasura atravessa a palavra, a linha ou o parágrafo, ela é ao mesmo tempo denegação que já foi escrito e espera do que vai surgir ${ }^{8}$

\footnotetext{
${ }^{7}$ BiAnCO, G. Conceitos em contexto: Diferença e repetição de Gilles Deleuze, (Curso) Ministrado USP, 2018.

${ }^{8}$ WILlemart, P. A escritura na era da indeterminação. São Paulo: Perspectiva, 2019, p. 80.
} 
Dessa forma, buscaremos explorar, ao longo deste artigo, dois caminhos possíveis para abordar esse modo específico de criação. Primeiramente será avaliada a possibilidade de encontrar em textos precedentes um espaço que se assemelha ao que a crítica genética tem chamado de avant-texte, ainda que por definição trata-se de espaços distintos. E, a partir da reescrita pós-editorial de Proust et les signes buscando recuperar traços geneticamente relevantes deste gênero de processos, por meio da comparação entre versões.

\section{Eragmentos do inicio de um relacionamento amoroso: um avant-texte possível}

Mesmo antes da publicação de Marcel Proust et les signes em 1964, Gilles Deleuze já se referia, com certa frequência e em diferentes escritos, à produção do autor de Em busca do tempo perdido. As primeiras alusões diretas à obra de Marcel Proust datam, na verdade, dos anos 40, mas se dispersam por toda a sua produção. Mais do que um simples tema para um ensaio monográfico em particular, grande parte de seus escritos estão entremeados de referências ao romance, o qual não só ocupa uma posição de relevância em seu pensamento, chegando a colocar-se como um dos próprios fundamentos do projeto filosófico de Deleuze, além de estar no cerne da esquizoanálise, enquanto prática que será proposta em conjunto com Félix Guattari, em 1972 - a Recherche, cumpre lembrar, é para ambos um romance esquizoide por excelência 9 .

Temos, por exemplo, num artigo publicado na revista Poésie em 1946, esta que seria sua primeira menção a Proust: uma breve observação a respeito do modo como a princesa de Laumes costumava adentrar os salões parisienses cujo valor não fosse condizente, a seu ver, com a posição social de prestígio que ela acredita ocupar. O que se verifica no salão da Marquesa de Saint-Euverte, uma aristocrata que, a despeito das aspirações de tornar célebres e bem frequentadas suas soirées musicais, fracassa constantemente: seja pela indiposição que a presença de Charles Swann nessa reuniões gera entre a parcela anti-semita do foubourg Saint Germain; por suas tentativas de cooptar, por meio de intrigas, convidados ilustres dos salões de Mme. Verdurin e de Mme. Bontemps; ou mesmo pelos desafetos de alguns dos membros da família Guermantes, a qual compartilharia das mesmasorigens da família de Laumes. Num gesto que exprime a superioridade e a arrogância propositalmente veladas, a princesa de Laumes, "para mostrar que ela não queria exibir, num salão onde apenas ia por condescendência, a superioridade do seu posto, ela havia entrado encolhendo os ombros, mesmo que não houvesse nenhuma multidão para afastar e ninguém para deixá-la passar"10.

Encontra-se, já neste texto de juventude, uma primeira formulação daquilo que Deleuze chamará de signo mundano ${ }^{11}$, anos depois:

O signo mundano surge como o substituto de uma ação ou de um pensamento, ocupando-lhes o lugar. Trata-se, portanto, de um signo que não remete a nenhuma outra coisa, significação transcendente ou conteúdo ideal, mas que usurpou o suposto valor de seu sentido. Por esta

\footnotetext{
${ }^{9}$ Cf. DeleuZe, G. ; GuAtTARI, F. O anti-Édipo. São Paulo: Editora 34, 2010, p. 63.

${ }^{10}$ Proust, M. A la recherche du temps perdu (tomes I). Paris: Gallimard, 1954 apud. DeleuZE, G. "Dizeres e perfis", in: DELEUZE, G. Cartas e outros textos. São Paulo: N-1 Edições, 2018, p. 279.

${ }^{11}$ Sobre elaboração conceitual referente à noção signo e suas tipologia em Proust e os signos, ver: ANTUNES, T. L. "Os signos em preparação: o devir conceito”, Manuscrítica, no 39, 2019, p. 5-20.
} 
razão a mundanidade, julgada do ponto de vista das ações, é decepcionante e cruel e, do ponto de vista do pensamento, estúpida. Não se pensa, não se age, mas emitem-se signos. ${ }^{12}$

Nessas circunstâncias, como nota Deleuze, a princesa encena a necessidade de produzir um afastamento, característica de alguém que tenta se desloca em meio a uma aglomeração, muito embora não houvesse qualquer justificativa para tal gesto - trata-se, pois, apenas da emissão de um signo. Ele não se refere àquilo que geralmente seria seu sentido, caso fosse uma ação: a abertura de um caminho por onde passar, já que a personagem "mesma se afasta e se deixa passar"13. Também não seria adequado afirmar que esse movimento é a expressão de um pensamento: isso porque, o gesto não tem como função reiterar a ideia que ela faz de si mesma, marcando a distinção social do lugar que ocupa entre as pessoas presentes naquele salão em particular. Antes, há uma sobreposição de um novo sentido, o qual consistiria em "mostrar que ela não queria exibir [...] a superioridade de seu posto [...]". A personagem produz um sinal: uma falsa tentativa de ocultar a disparidade, funcionando, justamente, como meio de torná-la ainda mais evidente a todos.

"A mundanidade transforma em seres históricos aqueles que participam de sua essência com mais brilhantismo" ${ }^{14}$, dirá Deleuze a propósito da personagem em questão. Mas o que é esse ser histórico e essa essência do mundano, nesse contexto? Seja em relação ao ser ou a um objeto, Deleuze define essa "historicização", no contexto, como processo que coloca fora de nosso alcance tal ser ou objeto: "O objeto histórico basta a si próprio e remete apenas a si próprio, ele é aquilo que se toca a si mesmo"15. Deleuze emprega, inclusive, uma figura inusitada para descrever fenômenos como esse: o onanismo, enquanto masturbação e também como uma gama de impulsos que conotam formas do autoerotismo ou de uma autorreferencialidade estrita de uma determinada postura ou comportamento. É bastante claro esse aspecto no gesto da princesa de Laumes - e são precisamente essas as características dos signos mundanos, tal como descritos em 1964:

\footnotetext{
O signo mundano não remete a alguma coisa; ele a "substitui", pretende valer por seu sentido. Antecipa ação e pensamento, anula pensamento e ação, e se declara suficiente. Daí seu aspecto estereotipado e sua vacuidade. [...] Eles são vazios, mas essa vacuidade lhes confere uma perfeição ritual, como que um formalismo que não se encontrará em outro lugar. Somente os signos mundanos são capazes de provocar uma espécie de exaltação nervosa, exprimindo sobre nós o efeito das pessoas que sabem produzi-los. ${ }^{16}$
}

Eis aqui, por um lado, a principal tarefa atribuída ao filósofo, ao menos neste momento de sua trajetória, a qual em muitos aspectos é coincidente com o foi realizado por Proust na Recherche: "A filosofia deve despojar os seres e as coisas de seu sentido pejorativo: trata-se de dar conta, e é tudo. Trata-se de descrever, e as coisas nada

\footnotetext{
12 DELEUZE, G. Proust e os signos. Rio de Janeiro: Forense Universitária, p. 6.

${ }^{13}$ DELEUZE, G. “Dizeres e perfis”, in: DELEUZE, G. Cartas e outros textos. São Paulo: N-1 Edições, 2018, p. 279.

${ }^{14}$ DELEUZE, G. “Dizeres e perfis”, in: DELEUZE, G. Cartas e outros textos. São Paulo: N-1 Edições, 2018, p. 279.

${ }^{15}$ DELEUZE, G. "Dizeres e perfis”, in: DELEUZE, G. Cartas e outros textos. São Paulo: N-1 Edições, 2018, p. 279.

${ }^{16}$ DELEUZE, G. Proust e os signos. Rio de Janeiro: Forense Universitária, p. 6.
} 
devem às nossas reprovações, às nossas apologias tampouco." ${ }^{17}$, delineando através dela "uma paixão fundamental, insuportável para alguns, que então a perfilam em ações sob forma de vícios" ${ }^{18}$.

Contudo, em "Dizeres e perfis" não encontramos até então uma série de elementos assimilados mais tarde, e que se tornam centrais na leitura que será desenvolvida na primeira edição do livro sobre Em busca do tempo perdido. Certamente, é possível recuperar traços dos processos de criação em marcha, porém, em outros escritos - em especial, nas resenhas que publicadas entre meados da década de 50 e o início dos 60 . Não há ainda, por exemplo, a articulação explícita ou o protagonismo das noções de signo, sistema, série ou grupo - todos elementos em torno dos quais se inaugura uma reflexão em resenhas de livros que aparentemente nada têm a ver com Proust ou seu romance, apesar de suscitar os mesmo problemas e questões, sem que a articulação entre eles seja efetivamente demarcada pelo autor. Ainda que aconteça num contexto de apresentação sumária de obras récem publicadas, mas que logo serão retomados e ampliados. incialmente, no diálogo com a concepção de uma filosofia do surrealismo, nas produções de Ferdinand Alquié, e, posteriormente, numa aproximação com o estruturalismo, na ocasião de um comentário sobre a obra Raymond Roussel, de Michel Foucault ${ }^{19}$.

$\mathrm{Na}$ ausência de manuscritos e documentos preparatórios de Proust et les signes, um obstáculo à abordagem genética característico dos escritos de Deleuze, fará parte das tarefas do pesquisador reconstituir, desse modo, não só traços de um processo de criação, mas tambémde fabricar, a partir das publicações precedentes, quando incidirem sobre os mesmos temas, uma espécie um tanto particular de avant-texte.

\section{Do estudo da gênese pós-editorial e suas abordagens}

Principalmente concentrada no estudo do avant-texte, ainda que essa não seja sua única preocupação ao longo dos anos, a crítica genética manteve uma relação íntima com os manuscritos e documentos preparatórios que precedem as obras estudadas, centrando seus esforços nos estágios que circunscrevem um espaço que, normalmente, é da ordem do privado. Com a publicação que se segue a essas etapas, "Deixaremos, progressivamente, o espaço do manuscrito em que tudo ainda é - por direito - possível, para entrar numa nova dimensão em que a intervenção do autor tornar-se-á (salvo casos exceptionais) cada vez mais pontual”20. Saindo, com isso, do espaço genético do avant-texte para dar lugar à história do texto - prática que se aproximaria mais da filologia, enquanto estudo das variantes de um texto, em estados posteriores ao bon à tirer (momento em que o texto está pronto para ser impresso) que marcaria o corte entre o avant-texte e o texto propriamente definitivo.

Então, como pensar em criação e em documentos de processo, quando tudo aquilo de que dispomos encontra-se restrito às diferentes edições de uma mesma obra - sem manuscritos, esboços, planos, apenas versões impressas do livro? A sugestão de Mahrer é, na verdade, em certa medida, abrir uma concessão: assumir

${ }^{17}$ Deleuze, G. "Dizeres e perfis”, in: Deleuze, G. Cartas e outros textos. São Paulo: N-1 Edições, 2018, p. 276, itálico do autor.

${ }^{18}$ DeleuZe, G. “Dizeres e perfis”, in: DeleuZe, G. Cartas e outros textos. São Paulo: N-1 Edições, 2018, p. 276.

${ }^{19}$ Cf. ANTUNES, T. L. “Os signos em preparação: o devir conceito”, Manuscrítica, no 39, 2019, p. 5-20.

${ }^{20}$ BIASI, P.-M. La génétique des textes. Paris: Nathan, 2000 apud. MAHRER, R. "La plume après le plomb: Poétique de la réécriture des œuvres déjà publiées”, in: Genesis, n 44, 2017, p. 45, tradução nossa: “On va quitter progressivement l'espace du manuscrit où tout est - en droit - encore possible, pour entre dans une nouvelle dimension où l'intervention de l'auter va devenir (sauf cas exceptionnel) de plus en plus ponctuelle”. 
o caráter atípico de um processo de criação que não necessariamente será cessado pelo surgimento do livro. Essa seria a marca própria a uma atividade de reescritura pós-editorial:

Parece então razoável partir numa outra direção, admitindo que nada pode significar em princípio a parada no processo de escritura. Nenhuma forma de acabamento do produto chega a romper a relação mantida entre o criador e sua obra; nem mesmo a lei se aventura a isso, a qual faz do autor o único reescritor legal de sua obra. Para que essa relação pereça, é necessário que o autor tenha perecido ou que sumam os registros escritos. "Nada jamais será definitivamente dito enquanto houver tempo diante de si, dado como esperança ao faltante". Essa é a maneira como Jean Peytard resumiu a condição humana da criação verbal. $O$ 'texto definitivo' é a seu modo, como o rascunho, à espera da reescritura. A partir disso torna-se possível pensar geneticamente a publicação. ${ }^{21}$

Embora se considere que as modificações tenham um caráter de correção pontual nesta fase, isto é, de ajustes num produto já essencialmente pronto, mais do uma retomada do processo de criação ${ }^{22}$, em Proust et les signes a primeira concepção não parece ser de todo adequada. Primeiramente, entre cada edição, Deleuze faz apenas modificações pontuais em relação ao texto apresentado nas versões precedente. No entanto, há ao mesmo tempo operações significativas em outra parte: nas adições de novos capítulos, na inversão da ordem em que alguns desses capítulos são apresentados, na delimitação de novos capítulos a partir de blocos de textos que eram, antes, um único capítulo. O que Deleuze realiza se distancia do retoque e coloca em cena elementos não previstos, nem indicados nas edições anteriores - em muitos pontos, chegando até a afirmar ideias que se contradizem e, no entanto, coexistem no texto ao invés de serem sobrepostas ou descartadas por completo a cada versão. A cada ampliação, outros processos são colocados em marcha, mas há também tudo aquilo que, nas etapas que se sucedem, permanece inalterado. Mesmo assim podemos afirmar que, ao ser enunciado novamente no ato de publicação, em um contexto distinto, adquire novos sentidos.

Quais são, com isso, os encaminhamentos possíveis de um estudo da gênese pós-editorial e em que ela difere da genética textual? Embora não faça parte da nossa proposta estudar manuscritos, nem se chegue a reconstituir o processo de criação de Deleuze, trata-se de uma abordagem que, apesar de diferir de certos direcionamentos da crítica genética, não chega a romper por completo seu vínculo, ao mesmo tempo em que possibilita dar à disciplina um olhar renovado: aquele de um estudo um pouco mais amplo, menos descritivo e centrado nas

\footnotetext{
${ }^{21}$ MAHRER, R. "La plume après le plomb: Poétique de la réécriture des œuvres déjà publiées”, in: Genesis, no 44, 2017, p. 21, tradução nossa: "Il paraît donc raisonnable de partir sur un autre pied en admettant que rien ne peut signifier par principe l'arrêt du processus d'écriture. Aucune forme d'achèvement du produit ne peut rompre la rélation qu'entretient le créateur avec son œuvre ; la loi ne s'y aventure pas même, qui fait de l'auteur l'unique réecrivain légal de son œuvre. Pour que cette relation périsse, il faut que périsse l'auteur ou que disparaisse la trace écrite. 'Rien n'est jamais définitivement dit tant que le temps est devant soi, donné comme espérance au locuteur'. Telle est la manière dont Jean Peytard a résumé la condition humaine de la création verbale. Le 'texte définitif' est à sa manière, comme le brouillon, en attente de réécriture. À partir de là devient possible de penser la publication génétiquemenet".

22 Cf. BiAsI, P.-M. La génétique des textes. Paris: Nathan, 2000.
} 
práticas de escrita, a fim de traçar novos caminhos interpretativos ${ }^{23}$. Essa perspectiva, cuja produtividade não se limita ao processo de criação no campo literário, possibilita um estudo do próprio ofício de escrever em diferentes contextos. Nesse sentido, o propósito deixa de ser reconstituir um processo de criação original: ao contrário, o intuito torna-se construir novas hipóteses e perguntas sobre a escrita em suas significações possíveis ${ }^{24}$. Os documentos deixam, assim, de serem considerados inertes, para serem:

[...] um acontecimento num tempo e espaço próprios ligados a uma série de condições de possibilidade históricas com as quais estão intrisecamente relacionados. Não se trata, pois, de partir dos documentos e chegar a um processo de criação, mas de entender as tensões e contradições, as descontinuidades nas quais eles operam e que operam neles. ${ }^{25}$

Esse modelo teórico propõe um diálogo entre as noções de campo e contexto enunciativo, aliado ao estudos das práticas de produção, circulação e recepção. De modo que a criação é tida "como processo coletivo, de um grupo de indivíduos, mas também de um tempo, de um contexto discursivo, de um campo intelectual, de uma prática de escrita" ${ }^{26}$. Destaca-se, ainda com respeito à relevância dos trabalhos centrados tais processos de reescritura, que o potencial de uma abordagem como essa é, precisamente, aquele o que ele esclarece sobre as práticas de escritura em momentos diferentes, as quais podem tanto sofrem deslocamentos nos intervalos entre reedições, quanto capaz de dar a ver mudanças de ordem ainda mais amplas que não se referem somente a uma obra individual, mas:

Frequentemente, colocamos em paralelo "a emergência [em torno do século XVIII] de uma ordem de discurso que é fundada na individualidade da escritura, na originalidade das obras e na consagração do escritor” à uma mudança profunda das práticas de escritura. A concepção imitativa da literatura desaparece ao mesmo tempo em que "a escritura colaborativa, o reaproveitamento de histórias já contadas, ou ainda, as revisões contínuas e as continuações de obras sempre abertas”. Uma genética atenta à fase pós-editorial das obras do século XVIII em diante será levada complexificar essa periodização paralela entre epstêmes e práticas scripturais. Pois uma reflexão tal envolve um exame daquilo que escrever e publicar significam para uma determina cultura. [...] Bastaria para tanto que o scriptor admita que o ato de publicação não transforma definitivamente o texto em obra e o escritor em autor de modo irreversível [...]. Os autores que exploram a fase pós-editorial assume, mais ou menos

\footnotetext{
${ }^{23}$ Sobre esses aspectos e reformulações de certos procedimentos da crítica genética, cf. PINO, C. A.; ZULAR, R. Escrever sobre escrever: Uma introdução crítica à crítica genética. São Paulo: WMF Martins Fontes, 2007; PINO, C. A. "Crítica genética: o que interpretar?”, in: Revista do Programa de Pós-Graduação da Universidade de Passo Fundo, volume 10, no 2, 2014.

${ }^{24}$ Cf. PINO, C. A. "Crítica genética: o que interpretar?”, in: Revista do Programa de Pós-Graduação da Universidade de Passo Fundo, volume 10, no 2, 2014.

${ }^{25}$ PINO, C. A.; ZULAR, R. Escrever sobre escrever: Uma introdução crítica à crítica genética. São Paulo: WMF Martins Fontes, 2007, p. 157.

${ }^{26}$ PINO, C. A.; ZULAR, R. Escrever sobre escrever: Uma introdução crítica à crítica genética. São Paulo: WMF Martins Fontes, 2007, p. 173.
} 
explicitamente, que a reedição é uma ocasião afortunada: aquela da conclusão, de um acabamento real ou de um novo acabamento ${ }^{27}$

Dessa forma, o que se discute nos trabalhos da revista Genesis no 44, cujo tema é "Après le texte" é o fato de a reescrita não estar necessariamente ligada a uma tentativa de corrigir erros, nem de adaptar sua linguagem a um outro público, mas uma reativação do elo produtivo que une o escritor ao seu texto e que não é rompido definitivamente pelo ato de publicação.

\section{As formas dominação das massas}

Como se dará efetivamente esse reconhecimento das diferenças prévio à interpretação das intervenções? Para a identificação das mudanças, entre artigos preliminares e suas respectivas edições ou entre edições, destacaremos aqui o software MEDITE (Machine pour l'étude diachronique et interprétative du travail de l'écrivain) que permite comparações entre pares de versões. O programa desmembra blocos comuns, a partir da sequência dos caracteres, que ocupam posições idênticas ou semelhantes nos dois textos, alinhando as versões e identificando três tipos de diferenças: inserções, supressões e substituições. Uma ferramenta que, apesar de suas limitações, tem se mostrado útil aos estudos que se concentram na fase pós-editorial da gênese - dentre os quais destacaremos o trabalho de Antonin Wiser ${ }^{28}$, "L'espace du style : sur les trois versions d'Éperons $(1973,1976,1978) "$.

O artigo propõe um estudo que se aproxima daquilo que será desenvolvido ao longo desta pesquisa. Ao analisar as três versões de Éperons, de Jacques Derrida, que foram publicadas em 1973, 1976 e 1978, o autor examina o processo de reescrita do filósofo, observando a introdução de um distanciamento responsável por multiplicar e deslocar o sentido do texto. A partir disso, abre-se um espaço para discutir o estilo: "operação de corte deste estilete que Derrida direciona a Nietzsche -, um espaço que, se é que ele existe, não é nada para além do descarte entre as diferentes versões"29. Os procedimentos analisados por Wiser vão numa direção que problematiza a concepção de obra publicada como unidade estável:

\footnotetext{
${ }^{27}$ MAHRER, R. “La plume après le plomb: Poétique de la réécriture des œuvres déjà publiées”, in: Genesis, no 44, 2017, p. 28, tradução nossa: "On a souvent mis en parallèle "l'émergence [autour du XVIIIe siècle] d'un ordre de discours qui se fonde sur l'individualisation de l'écriture, l'originalité des œuvres et le sacre de l'écrivain" avec un changement profond des pratiques d'écriture. La conception imitative de la littérature disparaitrait en même temps que "l'écriture collaborative, le réemploi d'histoire déjà racontées, ou encore, les continuelles révisions et continuations d'œuvres toujours ouvertes". Une génétique attentive à la phase post-éditoriale des ouvres du XVIIIle et au-delà sera amenée à complexifier cette périodisation parallèle entre épistèmes et pratiques scripturales. Car une telle réflexion doit faire intervenir un examen de ce qu'écrire et publier signfient pour une culture donnée. [...] Il suffit pour cela que le scripteur admette que l'acte de publication ne transforme pas définitivement le texte en œuvre et l'écrivain irréversiblement en auteur ; [...] Les auteur qui exploitent la phase post-éditoriale assument, plus ou moins ouvertement, que la réédition est une occasion heureuse : celle d'un parachèvement, d'un réel achèment ou d'un nouvel achèvement".

${ }^{28}$ Cf. WISER, A. "L'espace du style: sur les trois versions d'Éperons $(1973,1976,1978)$ de Jacques Derrida", in: Genesis, no 44, 2017.

${ }^{29}$ WISER, A. “L'espace du style: sur les trois versions d'Éperons $(1973,1976,1978)$ de Jacques Derrida”, in: Genesis, no 44, 2017, p. 156, tradução nossa: "opération de découpe de ce stylet que Derrida emprunte à Nietzsche -, dont le lieu, si c'en est encore un, n'est autre que l'écart entre les différentes versions”.
} 
O problema genético viria nesse sentido inquietar a instituição do texto, e conferir ao volume editado uma fluidez que ultrapassa o fechamento enclausurado por sua capa. Então a marcação notada entre as linhas, se ela produz a estrutura, é também aquilo que ameaça a forma e a força de sua unidade, $\left[\ldots . .{ }^{30}\right.$

Pensando somente no resultado da comparação entre o artigo preliminar de 1963, "L'unité de A la recherche du temps perdui" (18 páginas) e a primeira edição, Marcel Proust et les signes (90 páginas), por exemplo, é produzido um arquivo de 300 páginas, comparando em duas colunas as versões. Proust et les signes conta com seis versões, as quais só poderiam ser cotejadas pelo software apenas em pares, ou seja, 36 arquivos, à princípio, completamente distintos entre si e que tendem a ser mais extensos à medida em que o número de páginas, entre as versões, é significativamente aumentado a cada reedição - deixando ao pesquisador um total de 1800 páginas de comparação a serem analisadas.

É verdade que, por um lado, da massa de documentos produzida na comparação do MEDITE não serão encontradas "rasuras" em todas as páginas de cada arquivo. Certamente, há nessa massa comparações que podem ser descartadas de entrada. Por exemplo, comparar os artigos preliminares entre daria origem unicamente a colunas que não apresentam qualquer paralelismo para além das raras coincidências determinadas, poderíamos dizer, por mero acaso, não indicando, necessariamente, rastros de um trabalho de escritura. Mais do que nos fornecer respostas, o programa tem como função evidenciar nas transcrições os blocos que permanecem inaltarados em contraposição àqueles que houve alguma mutação. Torna-se, desse modo, imprescindível o exame, caso a caso, para suplantar manualmente as insuficiências do conjunto finito de regras e procedimentos lógicos estabelecidos pelos programadores para classificar os resultados do cotejo.

Porém, há como contornar essas limitações: nesse cenário, as marcas de trabalho - que equivaleriam às rasuras nos manuscritos - devem também ser literalmente fabricadas pelo pesquisador, do que de uma instância autoral. Rasuras de uma criação pós-editorial, que não coincidem em muitos aspectos às correções operados por scriptor, partindo das diferenças entre documentos. Ainda dependente, em grande medida da da perspectiva daquele que lida com esses materiais e coloca suas próprias hipóteses. Se não chegamos a uma reconstituição do processo de criativo, tampoco podemos almejar uma verdade única das relações possíveis entre esses documentos. Não havendo ambição em determinar o verdadeiro sentido escondido em meio à massa de documentos, muito menos de consagrar um autor com um gesto análogo ao da amiga da srta. Vinteuil, que pressagia o ofício da crítica genética, "en passant des années à débrouiller le grimoire laissé par Vinteuil, en établissant la lecture certaine de ces hiéroglyphes inconnus, l'amie de Mlle Vinteuil eu la consolation d'assurer au musicien dont elle avait assombrit les dernières années une gloire immortelle et compensatrice" ${ }^{\text {}} 1$, onde se espera chegar? O remorso produtivo da personagem da Recherche, o qual serve de motor à passagem do inacabado à obra, numa pretensa fidelidade retrospectiva à intenção fundamental do compositor, não é existe aqui. Muito pelo contrário, o que trabalho possível é, precisamente, aquele de jogar luz nos pontos que o autor,

30 WISER, A. "L'espace du style: sur les trois versions d'Éperons $(1973,1976,1978)$ de Jacques Derrida”, in: Genesis, no 44, 2017, p. 153, tradução nossa: "Le souci génétique viendrait en ce sens inquiéter l'institution du texte, et rendre au volume édité une fluidité qui déborde la clôture où l'enserre sa couverture. Alors la substitution remarquée entre les lignes, si elle produit la structure, est aussi ce qui menace la forme et la force de son unité, [...]".

${ }^{31}$ Proust, M. A la recherche du temps perdu (tome II). Paris: Gallimard, 1954, p. 262. 
seja qualquer que tenha sido o motivo, acabou apagando - algo que pode ocorrer desde o âmbito da escolha vocabular às mudanças mais amplas associadas a seu contexto enunciativo.

O leitor deve se perguntar, neste ponto: não há uma contradição entre o que foi apontado anteriormente com relação à uma abordagem genética que se distancia um pouco da descrição dos movimentos escriturais no manuscrito, concentrando-se nas práticas de escrita e nas condições de enunciabilidade? Não, exatamente. O objetivo não é descrever a comparação dos textos, mas utilizá-la apenas como indentificador de determinadas rasuras a serem interpretadas em articulação com o contexto enunciativo e com as práticas discursivas em que esses textos e modificações são trazidos à luz. O software é empregado para sinalizar vestígios de uma criação intermitente em vias de se fazer com o processamento das transcrições. Logo, o propósito do cotejo recai em fazer visíveis as modificações que são encobertas a cada nova versões e deslocamentos que de outro modo seriam permanentemente apagados.

Nesse sentido, o esforço talvez se aproxima mais da continuação póstuma ao projeto Capitalismo e esquizofrenia imaginada por David Foster Wallace, em Infinite Jest, a qual dá o nome de Incest and the Life of Death in Capitalist Entertainment $^{32}$ : uma obra teórica imaginária, deixada em estado inacabamento pelo filósofo, por meio da qual o romancista expande a reflexão em torno do capitalismo, inicialmente proposta em O anti-Édipo e Mil Platôs, voltada ao campo do entretenimento - a nova engrenagem central no capitalismo tardio. Obra nova, porém, nunca escrita, nem mesmo esboçada por Deleuze, mas que não deixa de ser um prolongamento de reflexões que estão, em maior ou menor grau, implicadas virtualmente naquilo que, de fato, foi escrito por Deleuze.

\section{Escrever, Suprimir, Esquecer: a identificação de rasuras}

Detalhes, à primeira vista pequenos, descartados e encobertos a cada nova versão e que tornam observáveis certos pontos de partida que serão ocultados ao longo dos anos. Como nota Anne Sauvagnargues, com relação a esse aspecto, “[...] não compreendemos nada em Deleuze se não recuperarmos metodicamente seu trabalho com as referências, que é muito frequentemente implícito e mascarado por suas reelaborações sucessivas" ${ }^{33}$. Problema esse que já se coloca, de forma clara e carregada de sentido, nas versões do primeiro parágrafo de Proust et les signes.

Trata-se de uma das motivações indicadas como centrais pelo filósofo com relação a leitura que elabora do romance proustiano: haveria um desejo de corrigir um erro na fortuna crítica da Recherche, o qual consistiria na importância excessiva atribuída à memória pelos comentadores ${ }^{34}$. Mas quais são os interlocutores aos quais se dirige esse apontamento? De Deleuze, especificamente, nunca obtivemos qualquer resposta que torne o apontamento menos vago. Precisar os atores entre os quais se refere a crítica, certamente, traria pistas importantes sobre a dinâmica desses escritos em seu contexto de enunciação.

\footnotetext{
32 WallaCe, D. F. Infinite Jest. Nova Iorque: Little, Brown and Company, 1996, p. 792.

33 Sauvagnargues, A. Deleuze et l'art. Paris: Presses Universitaire de France, 2006, p. 16, tradução nossa: "[...] on ne comprend rien à Deleuze si on ne restitue pas méthodiquement son travail de référence, qui est le plus souvent implicite et masqué par ses réelaborations sucessives".

${ }^{34}$ Deleuze, G. Cartas e outros textos. São Paulo: N-1 Edições, 2018, p. 88: "Creio que um livro, se ele merece existir, pode ser apresentado sob três aspectos rápidos: só podemos escrever um livro 'digno': 1) se a gente acha que os livros sobre o mesmo tema ou sobre um tema próximo caem num tipo de erro global (função polêmica do livro) [...] qual erro ele tenta combater; [...] para Proust e os signos: o erro é a memória”.
} 
Embora não seja possível descartar por completo a possibilidade de identificar os destinatários desta crítica em particular, temos num comentário suprimido e que fora apresentado no início do primeiro artigo preliminar e que não voltara a aparecer em nenhuma das versões posteriores do texto. O que nos leva a crer que o ponto de partida não esteja tão ligado a exemplos específicos da fortuna crítica de Proust - mas um problema nas traduções da Recherche para o inglês. Mais importante, nesse caso, do que o fato de a referência ter ou não sido dirigida a um crítico em particular, é o caráter estratégico dessa omissão: é ela que dá a Deleuze um pretexto para tomar para si a palavra. O comentário ocultado é justamente o ponto de partida de sua interpretação de Em busca do tempo perdido: a memória seria um problema secundário, já que a "busca" teria como sentido um percurso de aprendizagem pelo passará personagem Marcel antes dar início ao trabalho de escritura de sua obra. Na relavância equivocada que a crítica teria conferido ao papel da memória no romance, é que está baseada a motivação e a necessidade de uma outra chave à interpretação. O livro, por si mesmo, gera outros problemas a serem interpelados, dentre os quais estão os impulsos às novas enunciações.

É notável nas intervenções de Deleuze, seja entre um artigo preliminar e sua respectiva edição ou até entre edições somente, um trabalho de reescrita de caráter duplo: sútil, no que diz respeito às modificações de trechos já publicados e, ao mesmo tempo, drástica nas ideias que são incorporadas nas adições ao ensaio. Uma forma de variação em que o texto é repetido e se cita, em partes, as quais coexistem com enunciados novos a que estão articulados.

Tabela 1: Exemplo de comparação do primeiro artigo preliminar e da primeira edição

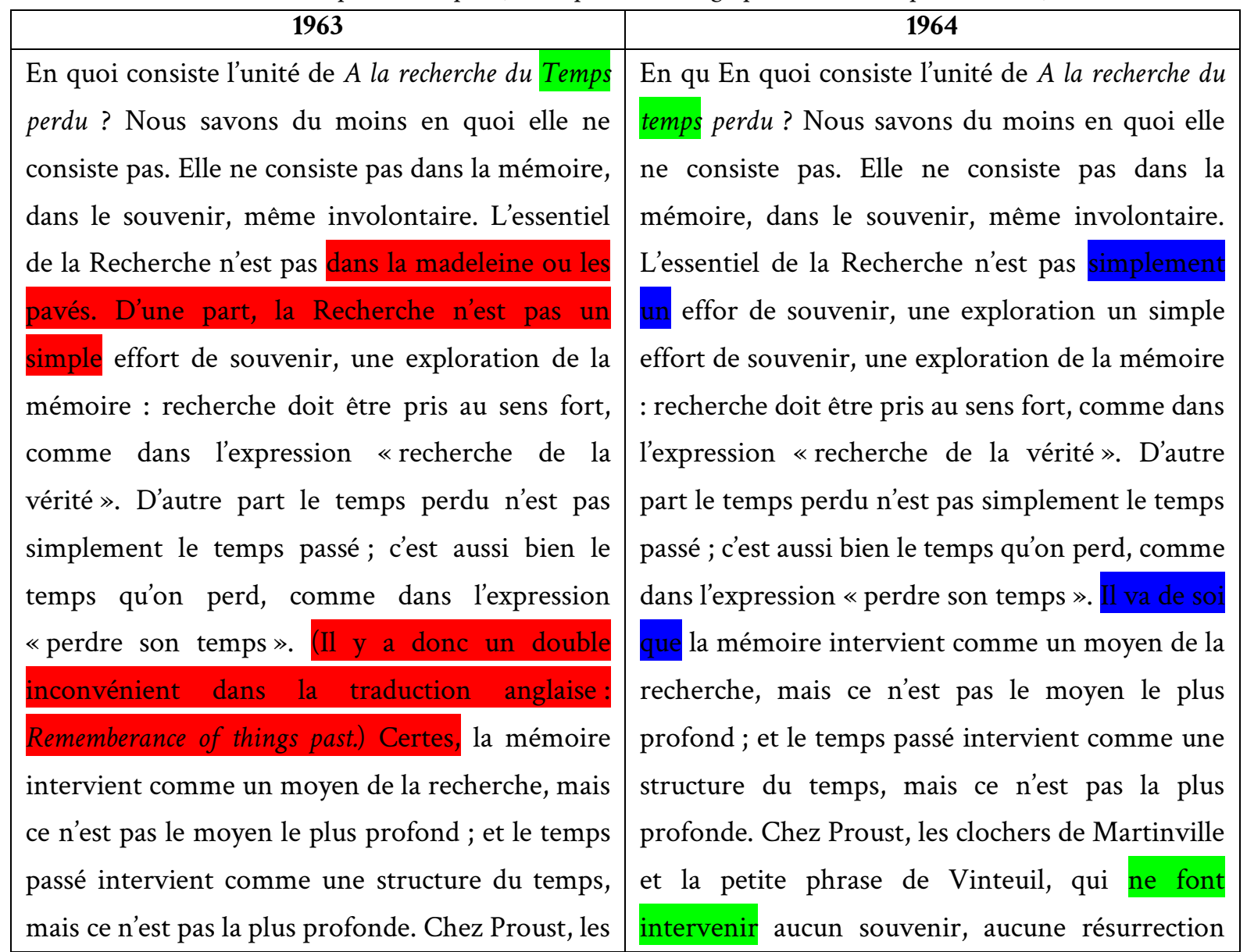




\begin{tabular}{|l|l|}
\hline clochers de Martinville et la petite phrase de & du passé, l’emporteront toujours sur la madeleine \\
Vinteuil, qui n'impliquent aucun souvenir, aucune & et les pavés de Venise, qui dépendent de la \\
résurrection du passé, l'emporteront toujours sur & mémoire, et, à ce titre, renvoient encore à une \\
la madeleine et les pavés de Venise, qui dépendent & ${\text { «explication matérielle }{ }^{36} \text {. }}^{\text {de la mémoire, et, à ce titre, renvoient encore à }}$ \\
${\text { une « explication matérielle }{ }^{35}}$ & supressão inserção substituição fixo \\
\hline
\end{tabular}

Fonte: Machine pour l'étude diachronique et interprétative du travail de l'écrivain (MEDITE).

A supressão do comentário a respeito da tradução do título em inglês de Em busca do tempo perdido, que desaparece por completo nas versões seguintes: Rememberance of things past. "Remembrance" que faz alusão, inevitavelmente, à lembrança e à recordação - o que, efetivamente, coloca a memória numa posição de destaque que não se aproxima do título original ou em língua portuguesa. Não se trata mais de uma busca, uma ação que também pode estar direcionada ao futuro, ao contrário da rememoração que, invariavelmente, implica uma relação com exclusiva entre presente e passado.

De certa forma, a supressão produzirá um efeito que existirá a despeito de qualquer intenção do filósofo: toda a discussão em torno de um do erro ligado ao protagonismo da memória, graças a esse apagamento, fará com que sua tese não esteja fundada apenas num mero problema de tradução que serviria de pretexto à perspectiva que ele expôs. Ao atribuir esse problema a uma corrente vagamente carcterizada, mais sem qualquer referencial preciso, torna-se um problema que justifica a intervenção do filósofo - ou, no limite, uma nota de repúdio à forma em que se traduziu o título do romance. Disso, a memória passará a ser contraposta à aprendizagem e à formação "de um homem de letras" 37 .

À medida em que se desenrola a análise das versões, nota-se que Deleuze apresenta um ponto problemático nas escolhas de um tradutor, discorre sobre esse problema e, no momento em que se efetua a ampliação do texto com a primeira edição, esses pontos de referência em que se ancoravam aspectos da reflexão - seu ponto de partida, por assim dizer - serão suprimidos definitivamente e caem no esquecimento, uma vez que as versões seguintes e de tiragens maiores circulam muito mais com as reimpressões do livro.

O mesmo gesto de obliteração não se dissocia de um movimento de expansão do texto. Ainda que em cada adição exista traços de uma "coerência rizomática de seu pensamento" ${ }^{38}$, o texto se desenvolve justamente através das descontinuidades. A reescritura em Deleuze é marcada pelo "o uso muito particular da retomada, do texto perpétuo que caracteriza a elaboração seu pensamento" ${ }^{39}$. Texto que não cessa de ser recriado, marcado por cortes e já anunciando, talvez numa escala menor, aquilo que será radicalizado no final dos anos 60 deslocamento que também afetará o estilo, as teses e as intervenções nas edições 1970 em diante:

\footnotetext{
${ }^{35}$ DeleuZE, G. "L’unité de A la recherche du temps perdu”, in: Revue de métaphysique et de morale, no 4, 1963, p. 427.

${ }^{36}$ DeleuZe, G. Marcel Proust et les signes. Paris: Presses Universitaire de France, 1964, p. 1.

${ }^{37}$ Deleuze, G. Proust e os signos. Rio de Janeiro: Forense Universitária, p. 3.

${ }^{38}$ Marantes, B. O. "Proust e Deleuze: mutualismos e criações”, in: Revista Limiar, volume 5, no 9, 2018, p. 59.

${ }^{39}$ Sauvagnargues, A. Deleuze et l'art. Paris: Presses Universitaire de France, 2006, p. 16, tradução nossa: "l'usage très particulier de la reprise, du texte perpétuel qui caractérise l'élaboration de sa pensée”.
} 
Se as obras Diferença e repetição e Lógica do sentido marcam uma espécie de salto no estilo de Deleuze, em direção a este outro uso da linguagem, é no encontro com Félix Guattari que se daria um salto ainda maior neste sentido. O tratamento da escrita enquanto fluxo é nitidamente radicalizado em $O$ anti-Édipo colocasse em prática ou escancarasse em seu próprio corpo - corpo do escrito - esta dinâmica do desejo, em uma escrita-fluxo-contínuo que carrega consigo mais diversos fragmentos de coisas, códigos, campos de saber, autores, conceitos. ${ }^{40}$

\section{Considerações finais}

De certo, trata-se de uma pesquisa ainda em curso e que conta paradoxalmente, apesar dos obstáculos iniciais com relação a falta de documentos de processo com os quais a crítica genética normalmente lida, com um número excessivo de materiais a serem analisados e comparados minuciosamente - um trabalho que não poderia ser esgotado nesse artigo e também, arriscaria afirmar, por este pesquisador individualmente. No entanto, embora a conclusão de fato seja um horizonte um tanto distante, o percurso proposto neste artigo busca indicar algumas possíveis soluções a um impasse que não se restringe à obra de Gilles Deleuze. Isso porque, mesmo que tenhamos abordado um ensaio sobre o romance de Proust, Em busca do tempo perdido, acredita-se que essas formas de "fabricar" um avant-texte - que, definitivamente não são as únicas - numa dimensão que, geralmente, é pouco considerada do ponto de vista das marcas de um processo de criação em vias de se fazer, assim como as possibilidades de reconstituir "rasuras" através da comparação de versões distintas entre si e publicadas, dão a ver deslocamentos geneticamente pertinentes.

Tomando como ponto de partida as primeiras alusões a Em busca do tempo perdido nos escritos de junventude do filósofo francês, encontramos elementos que serão fundamentais às teses apresentadas na leitura que será sistematizada e ampliada entre 1963 e 1976, com as diferentes versões do livro Proust et les signes, permeando uma série de escritos de Deleuze, inclusive aqueles que não teriam como eixo a proposição de um estudo centrado neste romance, especificamente.

Como vimos, é necessária uma concepção mais ampla, para tanto, dos aspectos levados em consideração pela crítica genética e do escopo daquilo que é tido como documento de processo: uma crítica menos descritiva e que não se limite aos movimentos escriturais em manuscritos e esboços preparatório, colocando em primeiro plano as implicações das práticas de escrita às quais o texto está atrelado, bem como as condições de enunciabilidade que lhe são próprias e que marcam os tipos e funções das intervenções que serão operadas pelo autor ao longo das reescrituras. Perspectiva que pode ser enriquecida e facilitada, em relação ao trabalho de cotejo das versões, por meio de softwares de processamento e comparação de texto - dentre os quais optamos pela exploração do programa desenvolvido pelo Institut des Textes et Manuscrits (ITEM), Machine pour l'étude diachronique et interprétative du travail de l'écrivain (MEDITE).

Uma gênese, portanto, concebida não como origem, nem mesmo como um processo uno, contínuo e linear, mas que é atravessada por descontinuidades, deslocamentos e, principalmente, introdutora de paradas seja no âmbito da escrita ou da leitura que atuam de modo análogo à rasura nos manuscritos, já que "A parada na leitura é parecida à do escritor quando rasura. A descontinuidade na leitura obriga o leitor a enxergar outras redes

${ }^{40}$ Malufe, A. C. “Aquém ou além das metáforas: a escrita poética na filosofia de Gilles”, in: Rev. Let., São Paulo, volume 25, 2012, p. 191. 
significantes e a dar outro sentido à sua leitura" ${ }^{41}$. Processo que, como tentamos mostrar, é reiterado em diferentes momentos da trajetória de Deleuze e de modo particularmente intenso em Proust et les signes, fazendo coexistirem num mesmo livro camadas distintas de texto que são incorporadas ao longo dos anos.

\section{Referências}

ANTUNES, T. L. "Os signos em preparação: o devir conceito", Manuscrítica, no 39, 2019, p. 5-20.

BIASI, P.-M. La génétique des texte. Paris: Nathan, 2000.

Deleuze, G. Cartas e outros textos. São Paulo: N-1 Edições, 2018.

DELEUZE, G. Deux regimes de fous: textes et entretient 1975-1995. Paris: Éditions de Minuit, 2003.

DELEUZE, G. "L'unité de A la recherche du temps perdu", in: Revue de métaphysique et de morale, no 4, 1963, p. 427.

DeleuZE, G. Marcel Proust et les signes. Paris: Presse Universitaire de France, 1964.

DeleuZe, G. ; Guattari, F. O anti-Édipo. São Paulo: Editora 34, 2010.

DELEUZE, G. Proust e os signos. Rio de Janeiro: Forense Universitária, 2003.

DELEUZE, G. Proust et les signes. Paris: Presses Universitaire de France, 1970.

DeLEuZE, G. Proust et les signes. Paris: Presses Universitaire de France, 1976.

MAHRER, R. “Anecdotique”, in: Genesis, no 44, 2017, p. 7-15.

MAHrer, R. "La plume après le plomb: Poétique de la réécriture des œuvres déjà publiées", in: Genesis, no 44, 2017, p. 17-39.

Malufe, A. C. "Aquém ou além das metáforas: a escrita poética na filosofia de Gilles", in: Rev. Let., São Paulo, volume 25, p. 185-204, 2012.

Marantes, B. O. "Proust e Deleuze: mutualismos e criações", in: Revista Limiar, volume 5, no 9, 2018.

PINO, C. A. "Crítica genética: o que interpretar?", in: Revista do Programa de Pós-Graduação da Universidade de Passo Fundo, volume 10, no 2, 2014, p. 259-273.

PINO, C. A.; ZULAR, R. Escrever sobre escrever: Uma introdução crítica à crítica genética. São Paulo: WMF Martins Fontes, 2007.

Proust, M. A la recherche du temps perdu (tomes I, II, III). Paris: Gallimard, 1954.

SAUVAGnARgues, A. Deleuze et l'art. Paris: Presses Universitaire de France, 2006.

W ALLACE, D. F. Infinite Jest. Nova Iorque: Little, Brown and Company, 1996.

Willemart, P. A escritura na era da indeterminação. São Paulo: Perspectiva, 2019.

WISER, A. "L'espace du style: sur les trois versions d' Éperons $(1973,1976,1978)$ de Jacques Derrida", Genesis, no 44, 2017, p. 144-156.

${ }^{41}$ Willemart, P. A escritura na era da indeterminação. São Paulo: Perspectiva, 2019, p. 181. 